\title{
ANALYTICAL PROCEDURE FOR THE DETERMINATION OF TULATHROMYCIN IN SWINE PLASMA
}

\author{
ANNA GAJDA, ANDRZEJ POSYNIAK, AND TOMASZ BŁĄDEK \\ Department of Pharmacology and Toxicology, \\ National Veterinary Research Institute, 24-100 Pulawy, Poland, \\ anna.gajda@piwet.pulawy.pl
}

Received: February 20, 2013

Accepted: May 15, 2013

\begin{abstract}
For the measurement of tulathromycin distribution in swine plasma an accurate and reliable analytical method was developed. The extraction was performed with oxalic acid buffer $(\mathrm{pH}=4.0)$. Plasma samples were cleaned up by solid phase extraction procedure using polymeric cartriges. Chromatographic separation was achieved on a $\mathrm{C} 18$ analytical column using mobile phase consisting of acetonitrile, $0.1 \%$ formic acid in gradient mode. Detection was carried out by liquid chromatography tandem mass spectrometry. Azithromycin was used as internal standard. The method has been successfully validated. The recovery from spiked samples ranged from $94 \%$ to $110 \%$. The limit of detection was $2 \mathrm{ng} / \mathrm{mL}$ and the limit of quantification was $5 \mathrm{ng} / \mathrm{mL}$. The method was developed to investigate the pharmacokinetics of tulathromycin in swine plasma. Applicability of the method was tested with plasma from swine administered with a single dose of tulathromycin.
\end{abstract}

Key words: swine, tulathromycin, plasma, validation.

Tulathromycin is a triamilide, long-acting macrolide antibiotic, used for the treatment of bovine and swine bacterial respiratory diseases. In pigs, it is effective against Actinobacillus pleuropnemoniae, Pasteurella multocida, and Mycoplasma hyopnemumoniae (11). This compound is a mixture of two isomers: $90 \%$ isomer A (15 membered macrocyclic ring) and 10\% isomer B (13 membered macrocyclic ring). Because tulathromycin in aqueous solutions exists as an equilibrated mixture of these two isomers, the antibiotic is produced as isomer $\mathrm{A}$. The isomer was quantitatively analysed in plasma $(7,8)$. A single dose of tulathromycin demonstrates a high clinical effectiveness after intramuscular injection to pigs. Tulathromycin is rapidly absorbed from the injection site with great bioavailability and long elimination half-life (3). Compared with older macrolides (erythromycin, tylosin, tilmicosin) widely used in veterinary medicine, structural modification of tulathromycin improved the pharmacokinetic properties of this new macrolide, as well as minimised the frequency of its administration (6).

Tulathromycin may be hydrolised to its metabolite - (2R, 3S, 4R, 5R, 8R, 10R, 11R, 12S, 13S, 14R)-2-ethyl-3, 4, 10, 13-tetrahydroxy-3, 5, 8, 10, 12, 14-hexamethyl-11-[[3, 4, 6-trideoxy-3-(dimethylamino)- $\beta$-D-xylo-hexopyranosyl]oxy]-1-oxa- 6-azacyclopentadecan-15-one (Tu-M). However, many analytical methods for the analysis of tulathromycin in plasma involve only parent compound. Tulathromycin slightly converts into its metabolite and thus, a very low concentration of the Tu-M was detected (13). Therefore, the analysis for pharmacokinetics purposes is focused only on unchanged tulathromycin. In the study, azithromycin was chosen as internal standard (IS), because of structural similarities between tri-basic tulathromycin and di-basic with 15-membered lactone ring - azithromycin, also belonging to macrolide group.

The aim of the study was to develop an efficient, accurate, and precise liquid chromatography tandem mass spectrometry (LC-MS/MS) analytical method for the determination of tulathromycin in swine plasma. The developed method has been validated with regard to criteria and recommendations included in FDA and EMEA Guidance for Bioanalytical Method Validation $(1,2)$.

\section{Material and Methods}

Reagents and chemicals. All organic solvents were HPLC grade and all chemicals were analytical grade. Acetonitrile and methanol originated from J.T. Baker ${ }^{\circledR}$ (Deventer, The Netherlands). Oxalic acid dihydrate (ACS) and dipotassium hydrogen phosphate came from POCh Gliwice (Poland). Trichloroacetic acid (TCA) and formic acid were obtained from SigmaAldich. Strata X TM $(33 \mu \mathrm{m}, 100 \mathrm{mg}, 6 \mathrm{~mL})$ solid phase extraction (SPE) columns were obtained from Phenomenex ${ }^{\circledR}$. Water was deionised $(>18 \mathrm{M} \Omega \mathrm{x} \mathrm{cm})$ inhouse by MilliQAdvantage system by Millipore. Analytical standard of tulathromycin (CAS: 217500-96- 
4, $>95 \%$ purity) and Draxxin ${ }^{\mathrm{TM}}$ medicinal product were purchased from Pfizer Pharmaceutical Company. Azithromycin (IS, CAS: 83905-01-5, > 95\% purity) was from Sigma-Aldrich.

Standard solutions. Individual stock standard solutions of tulathromycin and azithromycin $(1 \mathrm{mg} / \mathrm{mL})$ were prepared by dissolving $10 \mathrm{mg}$ of each compound in $10 \mathrm{~mL}$ of methanol. These solutions were stored in dark glass bottles at $20^{\circ} \mathrm{C}$ and were stable for at least 6 months. Working standard solution $(10 \mu \mathrm{g} / \mathrm{mL}$, $1 \mu \mathrm{g} / \mathrm{mL}$ ) of tulathromycin was prepared in $0.05 \mathrm{M}$ dipotassium hydrogen phosphate solution, whereas in case of azithromycin methanol was used as the solvent. Working standard solutions were made in glass bottles and stored at $4^{\circ} \mathrm{C}$. The standard solutions for calibration curve were prepared by dilution with $0.1 \%$ formic acid in water.

Sample preparation, extraction, and cleanup. Blood samples were collected from six swine nontreated with tulathromycin. The samples were immediately transferred into heparinised tubes and separated by centrifugation at $4,500 \mathrm{rpm} / \mathrm{min}$ for $10 \mathrm{~min}$ at $4^{\circ} \mathrm{C}$. The plasma was harvested and used as negative controls (blanks) and for the preparation of tulathromycin fortified controls.

One $\mathrm{mL}$ of swine plasma was measured into a $50 \mathrm{~mL}$ polypropylene centrifuge tubes. Then, $20 \mu \mathrm{L}$ of azithromycin $(10 \mu \mathrm{g} / \mathrm{mL})$ was placed as IS. The samples were mixed with $10 \mathrm{~mL}$ of $0.02 \mathrm{M}$ oxalic acid buffer ( $\mathrm{pH} 4.0$ ) and vortexed for $1 \mathrm{~min}$. Afterwards, $500 \mu \mathrm{L}$ of $5 \%$ TCA was added and the samples with the use of vortex were mixed for $2 \mathrm{~min}$ and centrifuged for $15 \mathrm{~min}$ at $4,500 \mathrm{rpm} / \mathrm{min}$ at $4^{\circ} \mathrm{C}$. The solid phase extraction (SPE) polymeric cartridges were preconditioned with 3 $\mathrm{mL}$ of methanol and $3 \mathrm{~mL}$ of water. The whole supernatant was poured onto SPE columns. After the percolation of the whole solution, the columns were washed with $3 \mathrm{~mL}$ of water, $6 \mathrm{~mL}$ of $6 \%$ methanol in water, and dried (under vacuum) for $10 \mathrm{~min}$. The tulathromycin was eluted with $6 \mathrm{~mL}$ of methanol and then the eluate evaporated completely under a stream of nitrogen at $45^{\circ} \mathrm{C}$. The evaporated residue was dissolved in $500 \mu \mathrm{L}$ of $0.1 \%$ formic acid in water, and mixed.

Liquid chromatography - mass spectrometry conditions. Analyses were performed on an Agillent 1200 HPLC system (Agilent Technologies) consisting of a quaternary pomp, an autosampler, a column heater, switching valve, and an automatic degasser (Agilent Technologies), and an API 4000 triple quadropule mass analyser with a TurboIonSpray source (Applied Biosystems, Canada). The MS detector was configured as electrospray ionisation (ESI). The ESI was operated in the positive ion mode and data acquisition was performed in the multiple reaction monitoring (MRM) mode, selecting one precursor ion to two products ion transitions for analyte. The Analyst 1.5 software controlled the LC-MS/MS system processed data. Nitrogen was used as nebuliser gas, curtain gas, and collision gas. TurbolonSpray source was operated at $300^{\circ} \mathrm{C}$ with the capillary voltage set at $5,500 \mathrm{~V}$.
The chromatographic separation was performed on a Luna C18 $(150 \times 2.0 \mathrm{~mm}, 3 \mu \mathrm{m})$ analytical column (Phenomenex) coupled with octadecyl guard column $(4 \times 2 \mathrm{~mm})$ (Phenomenex). The mobile phase was consisted of solvent A (acetonitrile) and solvent $\mathrm{B}(0.1 \%$ formic acid in water) (v/v). The elution was performed in a gradient mode. The gradient started with $5 \% \mathrm{~A}$ at 0 to $5 \mathrm{~min}, 50 \% \mathrm{~A}$ from 6 to $10 \mathrm{~min}$, and then $5 \% \mathrm{~A}$ at 12 to $15 \mathrm{~min}$. Flow rate was $250 \mu \mathrm{L} / \mathrm{min}$ at $30^{\circ} \mathrm{C}$, the injection volume was $30 \mu \mathrm{L}$ and time of analysis $-15 \mathrm{~min}$.

Animals and dosing. The experiment was conducted on five healthy pigs, weighing about $25 \mathrm{~kg}$. One pig, never treated with tulathromycin, was used as control (blank samples). Four other animals were treated individually with tulathromycin (Draxin ${ }^{\mathrm{TM}}{ }^{\circledR}, 2.5 \mathrm{mg} / \mathrm{kg}$ b.w.) administered i.m. at a single dose. Feed and water were available ad libitum. The plasma was collected at $12 \mathrm{~h}$ and $24 \mathrm{~h}$, and on $7^{\text {th }}$ and $14^{\text {th }} \mathrm{d}$ after administration of tulathromycin. All samples were kept separately at $-20^{\circ} \mathrm{C}$ until the analysis.

\section{Results}

Method development. The optimal conditions for sample preparation were obtained after comparative studies of different extraction solutions coupled with different SPE cartridges. The cleaning up with the Strata $\mathrm{X}$ cartridges followed by the extraction with oxalic acid buffer ( $\mathrm{pH} \mathrm{4}$ ) was found to be the most effective. The aim of the study was to develop a method of sample preparation with reduced extraction and clean-up steps. The elaborated method was not complicated and less time consuming. For quantitative analysis of tulathromycin, a liquid chromatography - mass spectrometry system was optimised. The MRM mode and the optimal conditions with transition parameters for the detection of tulathromycion are presented in Table 1. The dwell time for both transitions was $200 \mathrm{~ms}$. In order to select precursor ions, full scan spectra were obtained by injecting standard solution into a mass spectrometer. Different collision offset voltages were measured to obtain the most relative abundance of precursor ions and product ions.

The time of chromatographic analysis was short and tulathromycin was presented at $8^{\text {th }}$ min as a sharp and symmetrical peak with no interfering peaks and reasonably stable retention time. Fig. 1 shows chromatogram of swine plasma spiked with tulathromycin and azithromycin (IS).

Validation. Various parameters were investigated during validation process, such as accuracy, precision and limit of detection (LOD). According to FDA guidance for bioanalytical method validation, the lowest concentration of calibration curve (LLOQ) as limit of quantification (LOQ) was measured and validated. Samples were spiked at four concentration levels $(5,50,250,500 \mathrm{ng} / \mathrm{mL})$ to determine repeatability and within-laboratory reproducibility, as well as accuracy calculated as spike recovery. 
Table 1

Multiple reaction monitoring mode for the detection of tulathromycin

\begin{tabular}{cccccccc}
\hline Analyte & RT(min) & $\begin{array}{c}\text { Precursor } \\
(\mathrm{m} / \mathrm{z})\end{array}$ & $\begin{array}{c}\text { Product } \\
(\mathrm{m} / \mathrm{z})\end{array}$ & DP (V) & CE (V) & CXP (V) & Ion ratio \\
\hline Tulathromycin & 8.1 & 806.6 & 577.5 & 136 & 33 & 15 & $0.43 \pm 25$ \\
\hline Azithromycin (IS) & 8.9 & 749.5 & 591.2 & 89 & 40 & 15 & \\
\hline
\end{tabular}

RT - retention time, DP - declustering potential, CE - collision energy, CXP - cell exit potential

Table 2

Validation results of analytical method for determination of tulathromycin in swine plasma

\begin{tabular}{|c|c|c|c|c|}
\hline Parameter & \multicolumn{3}{|c|}{ Results } & \\
\hline Compound & \multicolumn{3}{|c|}{ Tulathromycin } & \\
\hline Linear regression equation, $(y=a x+b)$ & \multicolumn{3}{|c|}{$y=1.94 x+2.93$} & \\
\hline Correlation coefficient & \multicolumn{3}{|c|}{0.9996} & \\
\hline Linearity (working range), $\mathrm{ng} / \mathrm{mL}$ & \multicolumn{3}{|c|}{$5-750$} & \\
\hline Limit of detection, $\mathrm{ng} / \mathrm{mL}$ & \multicolumn{3}{|c|}{2.0} & \\
\hline Limit of quantification, $\mathrm{ng} / \mathrm{mL}$ & \multicolumn{3}{|c|}{5.0} & \\
\hline Level of spiked samples, $\mathrm{ng} / \mathrm{mL}$ & 5 & 50 & 250 & 500 \\
\hline Recovery, $\%$ & 111.2 & 110.1 & 103.8 & 94.9 \\
\hline Repeatability, CV\% & 9.1 & 8.0 & 3.3 & 3.0 \\
\hline Reproducibility, CV\% & 10.0 & 7.4 & 4.2 & 3.8 \\
\hline
\end{tabular}
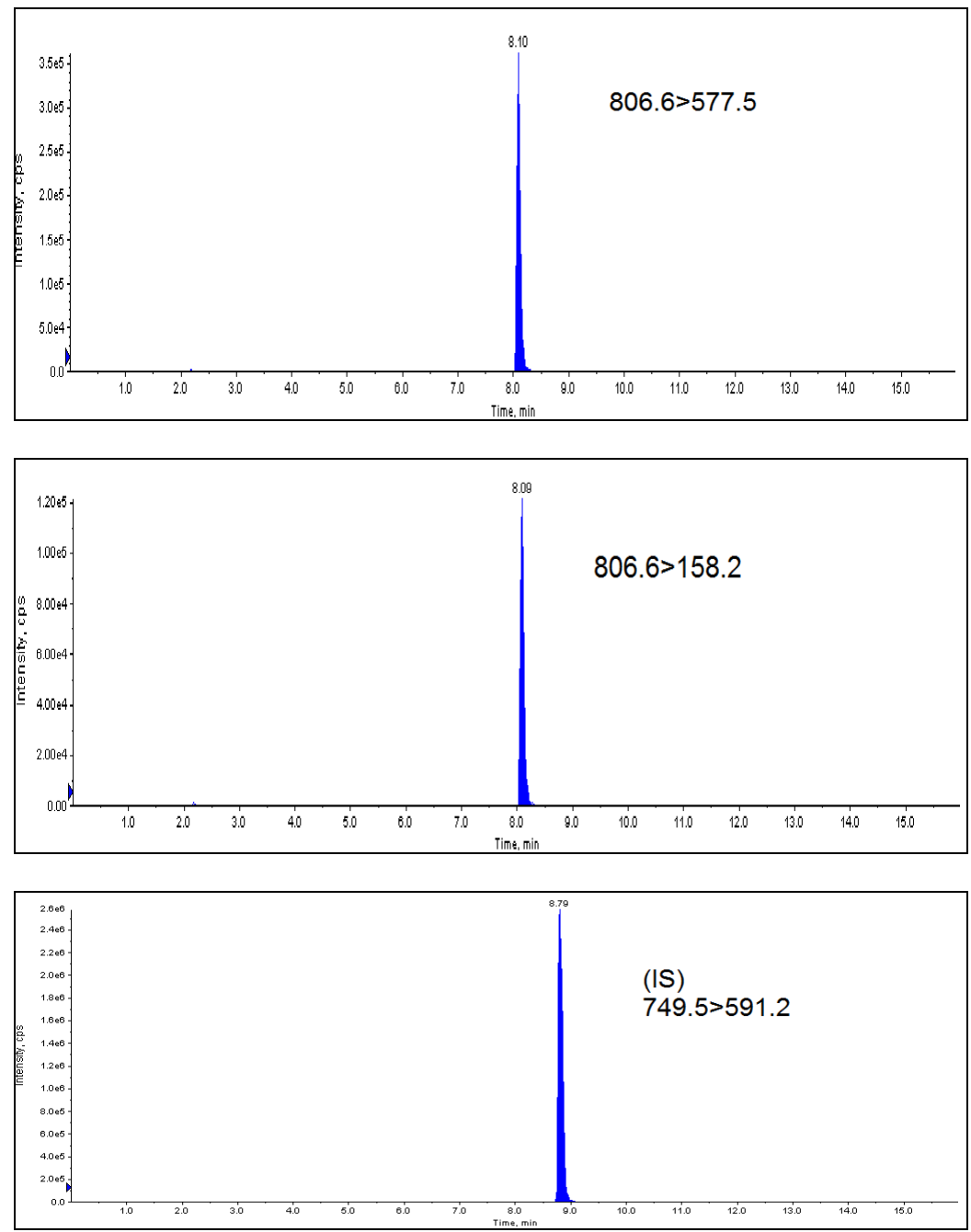

Fig. 1. Chromatograms of tulathromycin and internal standard in plasma fortified samples at the $50 \mathrm{ng} / \mathrm{mL}$ concentration level 
The results summarised in Table 2 showed a right accuracy ranging from $94.9 \%$ to $110.1 \%$ with a correct RSD, and less than $10.0 \%$ under withinlaboratory reproducibility. For the linearity, matrix calibration curve was prepared in duplicate at seven concentrations over the range of $5-750 \mathrm{ng} / \mathrm{mL}$. Correlation coefficient $\left(\mathrm{r}^{2}\right)$ presented in Table 2 was above 0.99 showing a high correlation between tulathromycin concentration and peak area. LOD and LOQ were calculated in spiked samples taking signal-tonoise ratios. The procedure was satisfactory sensitive, the LOD was established at the level of $2.0 \mathrm{ng} / \mathrm{mL}$, and the LOQ as $5.0 \mathrm{ng} / \mathrm{mL}$.

Stability of tulathromycin was also evaluated. Stock solutions $(1,000 \mu \mathrm{g} / \mathrm{mL})$ of tulathromycin and internal standard prepared in methanol has been stable for 6 months, kept at $-20^{\circ} \mathrm{C}$. Working standard solutions kept at $4{ }^{\circ} \mathrm{C}$ were stable for 3 months. For the evaluation of short-term stability three spiked samples, each at the concentration of 10 and $500 \mathrm{ng} / \mathrm{mL}$ were prepared and kept at room temperature for $24 \mathrm{~h}$. After this time, there were no significant variations in concentration of samples prepared and analysed immediately. To determine a long-term stability, spiked samples (10 and $500 \mathrm{ng} / \mathrm{mL}$ ) were analysed on the $1^{\text {st }} \mathrm{d}$ of preparation and then 1, 2, 3 months after their storage at $-20^{\circ} \mathrm{C}$. Comparing the concentration of tulathromycin from the $1^{\text {st }} \mathrm{d}$ of stability testing to concentrations of all analysed samples, the stability has been estimated for at least 3 months. After experimental administration of tulathromycin to pigs, plasma samples collected after 12 $\mathrm{h}, 24 \mathrm{~h}$, and $7 \mathrm{~d}$ showed positive results with HPLCMS/MS. The mean value of tulathromycin concentrations detected in plasma $12 \mathrm{~h}$ after treatment and $24 \mathrm{~h}$ after its administration were $207 \pm 21 \mathrm{ng} / \mathrm{mL}$ and $108 \pm 13 \mathrm{ng} / \mathrm{mL}$. During one week, the plasma concentration gradually declined to reach the mean value of $10 \pm 4.5 \mathrm{ng} / \mathrm{mL}$. After $14 \mathrm{~d}$, the concentration was below LOD of the method $(2 \mathrm{ng} / \mathrm{mL})$.

\section{Discussion}

The use of tulathromycin in treatment of respiratory infections in cattle and swine is becoming more and more frequent. Much higher concentration of this veterinary medicinal product was found in lungs of treated animals, indicating its good antibacterial effect $(3,15)$. Additionaly, it is a widely distributed, slow eliminated, and long-acting macrolide antibiotic. In order to measure its disposition and distribution in swine, a selective and accurate method was developed.

Many methods reported for the analysis of tulathromycin in plasma, as well as in biological matrixes involve SPE for the clean up purposes $(8,13)$. Especially in food matrices, when the method should detect the lowest values, the purification with solid phase extraction (SPE) is proven to be the most suitable approach. The clean up procedures including strong ion exchangers or cation exchange SPE cartridges have been described in the literature (8). For the wash solution in presented studies, a $5 \%$ methanol was chosen, because
Bohm et al. (4) have noted that higher percentage of methanol can cause a decrease in recovery of analite. Different sizes $(100,200,500 \mathrm{mg})$ of cartridges were tested, as well as Oasis HLB SPE columns were checked. Strata X cartridges were found to be the most suitable for clean-up, and the sizes of columns had no significant effect on the improvement of the recovery method.

Extraction is generally made using aqueous buffer system $(8,14)$. However, the extraction with acetonitrile or acetonitrile/ammonia $(95: 5, \mathrm{v} / \mathrm{v})$ has been also described (9). In this work, the authors applied an extraction process by oxalic acid buffer, followed by protein precipitation with tichloracetic acid, replacing the organic solvents widely used for extraction of this family of antibiotics.

Boner et al. (5) developed a method for the determination of tulathromycin residues in bovine liver and porcine kidneys. In their study, an isomer of tulathromycin (CP-472,295) was converted by acid hydrolysis into a common fragment, which was chosen as marker residues in tissues (CP-60,300).

To optimise the chromatographic conditions, Scheuch et al. (12) tested three d MS-RP-18 columns. However, the best results were obtained when separation columns were not used, thus a triple polyterafluorethylene filter system to mass spectrometry protection was applied. Different chromatography columns such as: Atlantis dC18, BDS Hypersil C8, Hypersil Gold C-18, and Ace 3 C8 columns with different mobile phases, were used to analyse the tulathromycin. The mobile phase comprised ammonium formiate buffer/acetonitrile, ammonium acetate $(\mathrm{pH} 4.0)$ with formic acid-acetonitrile, and methanol $/ 0.1 \%$ formic acid-ammonium formate aqueous solution $(12,13,14)$. In the presented method, the mobile phase consisted of $0.1 \%$ formic acid in water and acetinitrile, similarly to the procedure reported by Martos et al. (9). Different mobile phase $\mathrm{pH}$ values were tested in the study. It was noted that, the chromatographic peaks became more asymmetric and peaks tailing were observed when the values of $\mathrm{pH}$ used were increasing $(4.5,5.0,6.0)$. Thus, the acidic conditions were the most suitable to obtain sharp and symmetric peaks. Application of the LC$\mathrm{MS} / \mathrm{MS}$ technique overcomes the previous problems, i.e., the low specificity and inaccuracy encounter with both microbiological and HPLC - based assays.

Previous reports focused on other methods for determination of tulathromycin in the liver and kidneys (5), muscles (9), lungs $(3,8,10)$, and plasma $(8,10)$. Some of these studies used deuterated tulathromycin analog as IS (8). Galer et al. (8) presented the synthesis of heptadeutero tulathromycin derivate. However, based on stability testing, there were differences in behaviour between the parent veterinary medicinal product and its deuterated isomer. Degradation of the parent compound occurred to a greater extent than in case of its derivate. The usage of roxithromycin as IS was also presented $(12,13)$. In the study, the azithromycin as IS, with similar chemical structure and properties to tulathromycin, was applied. The choice of this compound proved to be correct, because the behaviour 
and stability were similar to tulathromycin, hence it turned out to be suitable for quantitative analysis.

Applicability of the presented method was tested in a pilot study, with plasma from swine administered with tulatromycin. The obtained results are comparable to those described in literature. Galer et al. (8) measured tulathromycin in swine and cattle plasma, comparing different doses $(0.94 \mathrm{mg} / \mathrm{kg}, 2.22 \mathrm{mg} / \mathrm{kg}$, and $4.77 \mathrm{mg} / \mathrm{kg}$ ). The results obtained over $24 \mathrm{~h}$ were about $30 \mathrm{ng} / \mathrm{mL}, 100 \mathrm{ng} / \mathrm{mL}$, and $150 \mathrm{ng} / \mathrm{mL}$, respectively. Benchaoui et al. (3) determined the pharmacokinetics of tulathromycin in swine after i.m. administration at a dose of $2.5 \mathrm{mg} / \mathrm{kg}$. The mean concentration of the antibiotics $24 \mathrm{~h}$ post dosing was slightly above 100 $\mathrm{ng} / \mathrm{mL}$, while $7 \mathrm{~d}$ after the administration of tulathromycin it was at the approximate level of 20 $\mathrm{ng} / \mathrm{mL}$. Benachaoui et al. (3) and Wang et al. (13) reported that tulathromycin reached maximal serum concentration within half an hour after its intramuscular injection. Twenty-four hours after injection, tulathromycin achieved peak concentration in the lungs and in plasma its concentration was much lower (3).

This study describes new, rapid, and highly quantitative liquid chromatography-mass spectrometry method, with good sensitivity, selectivity, and accuracy required to measure tulathromycin in swine plasma. A simple sample preparation and short HPLC run time enable performing many analyses in a very short time. All quality parameters fulfilled the international criteria for bioanalytical method validation. The satisfactory results of validation and preliminary results of the experiment proved, that the method presented in the study is precise and can be suitable for the analysis of tulathromycin distribution and its depletion in livestock plasma. More accurate pharmacokinetic studies with pharmacokinetic parameters determination, after experimental application of tulathromycin to swine, are planned.

Acknowledgements: This work was financially supported by the Ministry of Science and Higher Education (project NR N N 308575540).

\section{References}

1. Anon. U.S. Department of Health and Human Services, Food and Drug Administration (FDA), Center for Drug Evaluation and Research (CDER), Center for Veterinary Medicine: Guidance for Industry, Bioanalytical Method Validation, 2001

2. Anon. European Medicines Agency (EMEA): Guideline on bioanalytical method validation, 2011.

3. Benchaoui H.A., Nowakowski M., Sherington J., Rowan T.G., Sunderland S.J.: Pharmacokinetics and lung tissue concentrations of tulathromycin in swine. $\mathrm{J}$ Vet Pharmacol Therap 2004, 27, 203-210.
4. Bohm D.A., Stachel C.S., Gowik P.: Multi-method for the determination of antibiotics of different substance groups in milk and validation in accordance with Commission Decision 2002/657/EC. J Chromatogr A 2009, 1216, 8217-8223.

5. Boner P.L., Gottschall D.W., Kim-Kang H.: Determination and confirmation of tulathromycin residues in bovine liver and porcine kidney via their common hydrolytic fragment using high-performance liquid chromatography/tandem mass spectrometry. J AOAC Int 2011, 94, 436-445.

6. Charles L., Segreti J.: Choosing the right macrolide antibiotic. A guide to selection. Drugs 1997, 53, 349357.

7. Darrington R.T., Zhang L., Ji Q., Rafka R.J., Morton B.J.: Equilibrium, kinetics, and mechanism of acyl migration in tulathromycin, a novel triamilide antibiotic. AAPS Pharm Sci 2003, 5 , 1187-1189.

8. Galer D., Hessong S., Beato B., Risk J., Inskeep P., Weerasinghe C., Schneider R., Langer C., LaPerle J., Renouf D., Bessire A., Español E., Rafka R., Ragan C., Boettner W., Murphy T., Keller D., Benchaoui H., Nowakowski M.: An analytical method for the analysis of tulathromycin, an equilibrating triamilide, in bovine and porcine plasma and lung. J Agric Food Chem 2004, 52, 2179-2191.

9. Martos P.A., Lehotay S.J., Shurmer B: Ultratrace analysis of nine macrolides, including tulathromycin A (Draxxin), in edible animal tissues with minicolumn liquid chromatography tandem mass spectrometry. J Agric Food Chem 2008, 56, 8844-8850.

10. Nowakowski M.A., Inskeep P.B., Risk J.E., Skogerboe T.L., Benchaoui H.A., Meinert T.R., Sherington J., Sunderland S.J.: Pharmacokinetics and lung tissue concentrations of tulathromycin, a new triamilide antibiotic in cattle. Vet Therap 2004, 5, 60-74.

11. Nutsch R.G., Hart F.J., Rooney K.A., Weigel D.J., Kilgore W.R., Skogerboe T.L.: Efficacy of tulathromycin injectable solution for the treatment of naturally occurring swine respiratory disease. Vet Therapeutics: Res Appl Vet Med 2005, 6, 214-224.

12. Scheuch E., Spieker J., Venner M., Siegmund W.: Quantitative determination of the macrolide antibiotic tulathromycin in plasma and broncho-alveolar cells of foals using tandem mass spectrometry. J Chromatogr B 2007, 850, 464-470.

13. Wang X., Tao Y.F., Huang L.L., Chen D.M., Yin S.Z., Ihsan A., Zhou W., Su S.J., Liu Z.L., Pan Y.H., Yuan Z.H.: Pharmacokinetics of tulathromycin and its metabolite in swine administered with an intravenous bolus injection and a single gavage. $\mathrm{J}$ Vet Pharmacol Therap 2012, 35, 282-289.

14. Young G., Smith G.W., Leavens T.L., Wetzlich S.E., Baynes R.E., Mason S.E., Riviere J.E., Tell L.A.: Pharmacokinetics of tulathromycin following subcutaneous administration in meat goats. Res Vet Sci 2011, 90, 477-479.

15. Zhanel G.G., Dueck M., Hoban D.J., Vercaigne L.M., Embil J.M., Gin A.S., Karlowski J.A.: Review of macrolides and ketolides - focus on respiratory tract infections. Drugs 2001, 61, 443-498. 